\title{
Implementing new advanced airway management standards in the Hungarian physician staffed Helicopter Emergency Medical Service
}

\author{
Akos Soti ${ }^{1,2^{*}}$, Peter Temesvari ${ }^{1,2}$, Laszlo Hetzman ${ }^{1}$, Attila Eross ${ }^{1}$ and Andras Petroczy ${ }^{1,2}$
}

\begin{abstract}
In 2011 the Hungarian Air Ambulance Nonprofit Limited Company introduced a new Rapid Sequence Intubation standard operating procedure using a template from London's Air Ambulance. This replaced a previous ad-hoc and unsafe prehospital advanced airway management practice. It was hoped that this would increase clinical standards including internationally comparable results. All Rapid Sequence Intubations performed by the units of the Hungarian Air Ambulance under the new procedure between June 2011 and November 2013 were reviewed in a retrospective database analysis. During this period the air ambulance units completed 4880 missions with 433 intubations performed according to the new procedure. The rate of intubations that were successful on first attempt was 95.4\% (413), while intubation was successful overall in $99.1 \%$ (429) of the cases; there was no failed airway. 90 complications were noted with 73 (16.9\%) patients. Average on scene time was 49 minutes (ranging between: 15-110 minutes). This data shows that it is possible to effectively change a system that was in place for decades by implementing a new robust system that is based on a good template.
\end{abstract}

Keywords: Prehospital, Rapid sequence intubation, Advanced airway, Success rate, Helicopter emergency medical service

\section{Background}

The Hungarian Air Ambulance Nonprofit Ltd. is the only Helicopter Emergency Medical Service (HEMS) provider in Hungary operating from 7 air bases with $100 \%$ physician manned helicopters in daylight hours. Prehospital endotracheal intubation has been routine in the last few decades in Hungary, but until recently, no effort was made to standardize indications or procedures for drug assisted intubation. Muscle relaxant drugs were never used (not even by anaesthetists) in prehospital care. This practice has never been thoroughly audited nor any data published on it. In 2010 the results of a local audit strengthened the suspicion that the previously described practice didn't meet internationally published standards. Although the overall success rate of intubation was $100 \%$ in these cases, first attempt success rate was well below optimal and a high complication rate suggested the system might be unsafe. (n: 38,

\footnotetext{
*Correspondence: akossoti@gmail.com

'Hungarian Air Ambulance Nonprofit Ltd., Legimentok u. 8, Budaors H-2040, Hungary

${ }^{2}$ National Ambulance Service, Robert K. krt 77, Budapest H-1134, Hungary
}

success: $100 \%$, success on first attempt: $68 \%$, complications: 39\%) [Hungarian Air Ambulance, non-published data].

The need for prehospital advanced airway management (especially endotracheal intubation) is still a debated topic $[1,2]$. Prehospital endotracheal intubation only improves outcome if performed in a governance system focused on patient safety [3]. In 2011 a decision was made to change the ad hoc and unsafe practice and to implement a new RSI Standard Operating Procedure (SOP) for the HEMS units. The aim was to achieve high clinical standards and internationally comparable results.

\section{Standard operating procedure and clinical governance}

Authors used the SOP of London's Air Ambulance with their help and consent as a template [4]. The reasons behind this decision were that this SOP was highly successful with the London Service, the authors had firsthand experience with it and it is a part of a robust Clinical Governance framework [5,6]. One of the key features of this SOP is to optimize the first attempt at laryngoscopy 


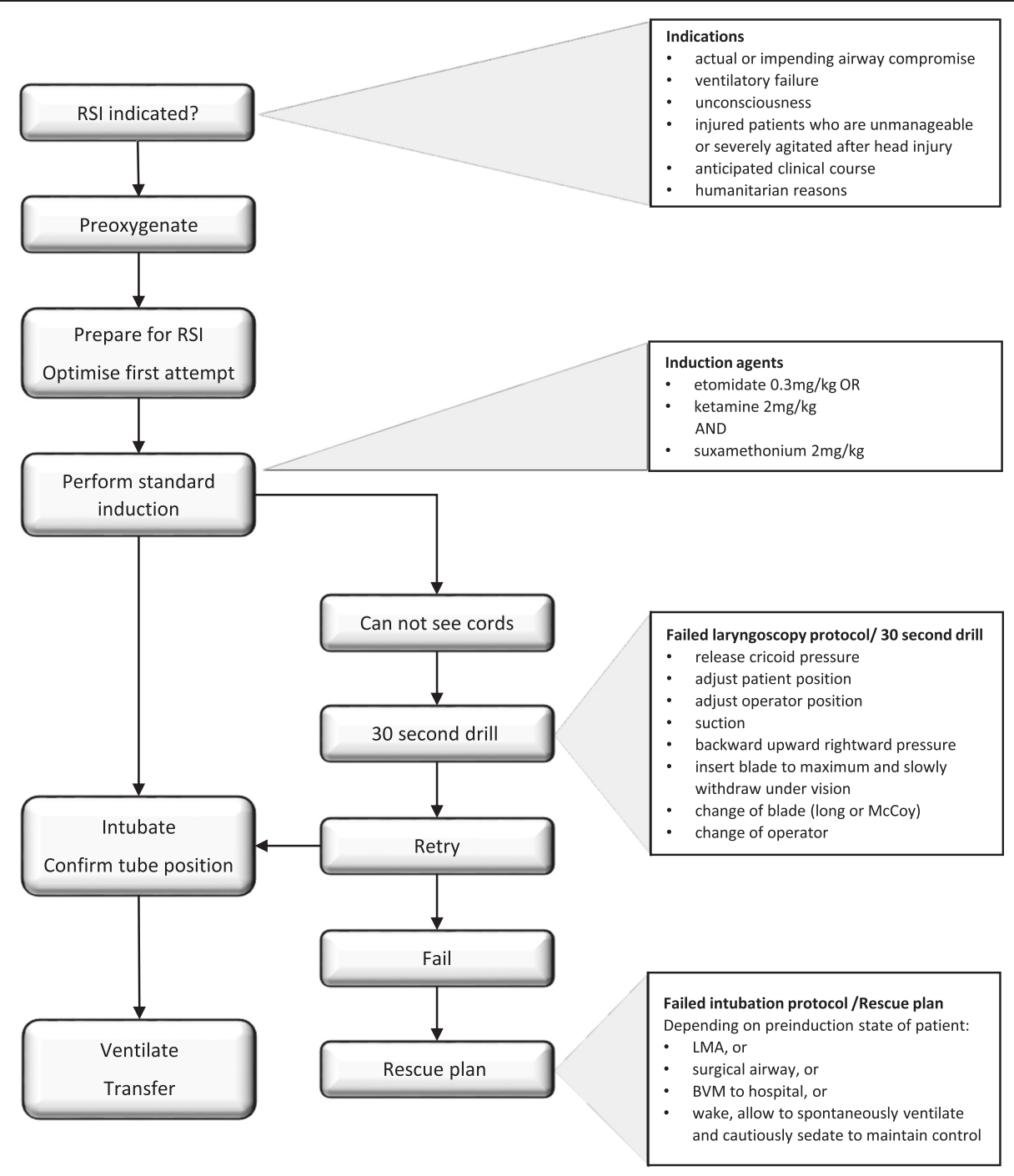

Figure 1 RSI algorithm.

while providing backup plans for failed laryngoscopy and for failed intubation [Figure 1].

Before intubation, the prehospital team goes through a challenge-response checklist. Application of cricoid pressure was optional, with a low threshold to release if it obstructed the operator's view $[7,8]$.

Implementing the SOP came with building up the elements of the earlier non-existent clinical governance as well $[6,9]$. There was a need for some drugs and extra equipment and also to rearrange the equipment carried by teams. All HEMS staff took part in simulation training over two days with a qualifying exam on completion. This required first training the instructors by those with recent UK (United Kingdom) HEMS experience.

Continuous refresher courses were introduced to establish currency after implementing the system. All
HEMS staff and all RSI cases were audited on a regular basis. We have implemented an on call consultant system, with consultants available via phone during service hours - we expected clinicians to make a short phone consultation before every procedure.

\section{Table 1 Indications for RSI}

\begin{tabular}{lll}
\hline Indications for RSI & $\mathbf{n}$ & \% \\
\hline Actual or impending airway compromise & 42 & 9.7 \\
Ventilatory failure & 56 & 12.9 \\
Unconsciousness & 271 & 62.6 \\
Injured patients who are unmanageable or severely & 51 & 11.8 \\
agitated after head injury & & \\
Anticipated clinical course & 13 & 3.0 \\
Humanitarian reasons & 0 & 0.0 \\
\hline
\end{tabular}


Table 2 Sub-group analysis of laryngoscopy attempts, complications and on scene time

\begin{tabular}{|c|c|c|c|c|c|c|c|c|c|c|c|c|c|c|c|c|c|c|c|c|c|c|c|c|c|c|c|}
\hline & & \multirow{2}{*}{\multicolumn{2}{|c|}{$\begin{array}{l}\text { Summary } \\
n: 433 \\
(100 \%)\end{array}$}} & \multicolumn{10}{|c|}{ Trauma } & \multicolumn{14}{|c|}{ Medical } \\
\hline & & & & \multirow{2}{*}{\multicolumn{2}{|c|}{$\begin{array}{l}\text { All trauma } \\
65.1 \%\end{array}$}} & \multirow{2}{*}{\multicolumn{2}{|c|}{$\begin{array}{l}\text { Isolated } \\
\text { head injury } \\
19.1 \%\end{array}$}} & \multirow{2}{*}{\multicolumn{2}{|c|}{$\begin{array}{l}\text { Burns } \\
6.7 \%\end{array}$}} & \multirow{2}{*}{\multicolumn{2}{|c|}{$\begin{array}{l}\text { Hanging } \\
2.1 \%\end{array}$}} & \multirow{2}{*}{\multicolumn{2}{|c|}{$\begin{array}{l}\text { Other } \\
37.2 \% \\
\end{array}$}} & \multirow{2}{*}{\multicolumn{2}{|c|}{$\begin{array}{l}\text { All medical } \\
34.9 \%\end{array}$}} & \multirow{2}{*}{\multicolumn{2}{|c|}{$\begin{array}{l}\text { Stroke } \\
8.3 \%\end{array}$}} & \multirow{2}{*}{\multicolumn{2}{|c|}{$\begin{array}{l}\text { Intoxication } \\
7.2 \%\end{array}$}} & \multirow{2}{*}{\multicolumn{2}{|c|}{$\begin{array}{l}\text { Status } \\
\text { epilepticus } \\
5.1 \%\end{array}$}} & \multirow{2}{*}{\multicolumn{2}{|c|}{$\begin{array}{l}\text { Ventilatory } \\
\text { failure } \\
4.2 \%\end{array}$}} & \multirow{2}{*}{\multicolumn{2}{|c|}{$\begin{array}{l}\text { Post - ROSC } \\
3.2 \%\end{array}$}} & \multirow{2}{*}{\multicolumn{2}{|c|}{$\begin{array}{l}\text { Other } \\
6.9 \%\end{array}$}} \\
\hline & & & & & & & & & & & & & & & & & & & & & & & & & & & \\
\hline & & $\mathrm{n}$ & $\%$ & $\mathrm{n}$ & $\%$ & $n$ & $\%$ & $\mathbf{n}$ & $\%$ & $\mathrm{n}$ & $\%$ & $\mathbf{n}$ & $\%$ & $\mathrm{n}$ & $\%$ & $\mathbf{n}$ & $\%$ & $\mathrm{n}$ & $\%$ & $\mathrm{n}$ & $\%$ & $\mathrm{n}$ & $\%$ & $\mathbf{n}$ & $\%$ & $n$ & $\%$ \\
\hline \multirow{4}{*}{$\begin{array}{l}\text { Attempts at } \\
\text { laryngoscopy }\end{array}$} & 1th & 413 & 95.4 & 269 & 95.4 & 80 & 96.4 & 27 & 93.1 & 9 & 100 & 153 & 95.0 & 144 & 95.4 & 36 & 100 & 28 & 90.3 & 21 & 95.5 & 18 & 100 & 12 & 85.7 & 29 & 96.7 \\
\hline & 2 th & 15 & 3.5 & 10 & 3.5 & 3 & 3.6 & 1 & 3.4 & & & 6 & 3.7 & 5 & 3.3 & & & 2 & 6.5 & 1 & 4.5 & & & 1 & 7.1 & 1 & 3.3 \\
\hline & 3th & 1 & 0.2 & 1 & 0.4 & & & & & & & 1 & 0.6 & & & & & & & & & & & & & & \\
\hline & Failed & 4 & 0.9 & 2 & 0.7 & & & 1 & 3.4 & & & 1 & 0.6 & 2 & 1.3 & & & 1 & 3.2 & & & & & 1 & 7.1 & & \\
\hline \multirow[t]{8}{*}{ Complications } & Hypotension & 35 & 8.1 & 23 & 8.2 & 4 & 4.8 & 3 & 10.3 & 2 & 22.2 & 14 & 8.7 & 12 & 7.9 & & & 4 & 12.9 & 3 & 13.6 & 4 & 22.2 & 1 & 7.1 & & \\
\hline & Desaturation & 35 & 8.1 & 19 & 6.7 & 4 & 4.8 & 1 & 3.4 & 1 & 11.1 & 13 & 8.1 & 16 & 10.6 & 4 & 11.1 & & & 3 & 13.6 & 2 & 11.1 & 4 & 28.6 & 3 & 10.0 \\
\hline & Aspiration & 5 & 1.2 & 3 & 1.1 & 1 & 1.2 & 1 & 3.4 & & & 1 & 0.6 & 2 & 1.3 & & & & & & & & & 2 & 14.3 & & \\
\hline & Bleeding & 5 & 1.2 & 2 & 0.7 & 1 & 1.2 & & & & & 1 & 0.6 & 3 & 2.0 & & & 1 & 3.2 & & & & & 2 & 14.3 & & \\
\hline & Misplacement & 3 & 0.7 & 3 & 1.1 & 2 & 2.4 & & & & & 1 & 0.6 & & & & & & & & & & & & & & \\
\hline & Hypertension & 3 & 0.7 & 1 & 0.4 & 1 & 1.2 & & & & & & & 2 & 1.3 & 1 & 2.8 & & & & & & & & & 1 & 3.3 \\
\hline & Dental injury & 2 & 0.5 & 1 & 0.4 & & & & & & & 1 & 0.6 & 1 & 0.7 & & & & & & & & & 1 & 7.1 & & \\
\hline & Bradycardia & 2 & 0.5 & 1 & 0.4 & & & & & & & 1 & 0.6 & 1 & 0.7 & & & & & 1 & 4.5 & & & & & & \\
\hline \multirow{4}{*}{$\begin{array}{l}\text { On scene time } \\
\text { (hh:mm) }\end{array}$} & Mean & \multicolumn{2}{|l|}{$0: 49$} & \multicolumn{2}{|l|}{$0: 47$} & \multicolumn{2}{|c|}{$0: 46$} & \multicolumn{2}{|c|}{$0: 49$} & \multicolumn{2}{|c|}{$0: 44$} & \multicolumn{2}{|l|}{$0: 53$} & \multicolumn{2}{|l|}{$0: 53$} & $0: 50$ & & $0: 51$ & & $0: 59$ & & $0: 54$ & & $0: 45$ & & $0: 5$ & \\
\hline & Standard deviation & $0: 14$ & & $0: 12$ & & $0: 13$ & & $0: 11$ & & $0: 11$ & & $0: 12$ & & $0: 16$ & & $0: 16$ & & $0: 13$ & & $0: 18$ & & $0: 18$ & & $0: 12$ & & $0: 1$ & \\
\hline & Minimum & $0: 15$ & & $0: 20$ & & $0: 20$ & & $0: 25$ & & $0: 31$ & & $0: 21$ & & $0: 15$ & & $0: 20$ & & $0: 20$ & & $0: 32$ & & $0: 30$ & & $0: 15$ & & $0: 3$ & \\
\hline & Maximum & 1:50 & & 1:32 & & 1:32 & & $1: 17$ & & 1:01 & & 1:31 & & $1: 50$ & & 1:21 & & $1: 23$ & & 1:50 & & $1: 23$ & & 1:04 & & $1: 4$ & \\
\hline
\end{tabular}




\section{Method}

We have completed a retrospective database audit on all bases involved from June 2011 till November 2013, summing 30 months of data. All patients intubated by HEMS using RSI were included. Cardiac arrests and patients not intubated by HEMS were excluded. We looked at the number of attempted laryngoscopies, failed laryngoscopy protocol elements used, and also documented any complications in different patient sub-groups. An intubation attempt was defined as attempted laryngoscopy with the intent to intubate. Blood pressure increase or decrease was recorded as a complication when the change after induction was more than $20 \%$ compared to the preinduction value. Desaturation was recorded as a drop of saturation after induction to below 90\%. Aspiration was identified as any tracheal soiling of saliva, gastric contents or blood. We have identified bleeding as any bleeding caused by laryngoscopy. Bradycardia was documented when heart rate went below $50 / \mathrm{min}$. Complications had to be procedure related (not present before induction). We also documented on scene times. For data collection we have used the patient documentation software "Esetlap 2006" by Tamas Gaspar. For further analysis, Microsoft Office Excel $^{(} 2013$ was used.

\section{Results}

In the observed period HEMS units completed 4880 missions, and performed 433 intubations following the new RSI SOP. Mean patient age was $46 \pm 22$ year ( 4 month -97 ), with the sex ratio of $72 \%$ male and $28 \%$ female. Indications are shown in Table 1.

Success of first attempt at laryngoscopy was recorded in $413(95.4 \%)$ cases. A second laryngoscopy was successful in 15 cases $(3.5 \%)$, and in one case $(0.2 \%)$ a third attempt was needed to pass the tube. Altogether out of the 433 patients we have managed to successfully intubate 429 (99.1\%).

In the remaining 4 cases $(0.9 \%)$ the intubation was unsuccessful. In 2 cases the airway was managed with a LMA, in the other 2 cases with surgical airway. Failed airway was not documented [Table 2].

The 30 second drill (failed laryngoscopy protocol) was used in 93 patients (21.5\%) in different combinations adding up to 154 elements used altogether [Table 3]. Cricoid pressure was applied in only $13(3 \%)$ cases. Out of these cases, it had to be released in 7 incidents $(53.8 \%$ of the cases where it was applied).

There were 90 complications in 73 patients. The mean on scene time was $49 \pm 14$ (15-110 minutes). Sub-group analyses are shown in Table 2 .

\section{Discussion}

Hungarian prehospital advanced airway management was previously based on ad hoc practice and individual
Table 3 Elements of failed laryngoscopy protocol

\begin{tabular}{lcc}
\hline Elements of failed laryngoscopy protocol (30 second drill) & $\mathbf{n}$ & $\mathbf{\%}$ \\
\hline Release cricoid pressure & 7 & 1.6 \\
Adjust patient position & 9 & 2.1 \\
Adjust operator position & 9 & 2.1 \\
Suction & 55 & 12.7 \\
Backward upward rightward pressure (BURP) & 39 & 9.0 \\
Insert blade to maximum and slowly withdraw under vision & 22 & 5.1 \\
Change of blade & 9 & 2.1 \\
Change of operator & 4 & 0.9 \\
\hline
\end{tabular}

decision making. With the implementation of the new robust RSI SOP we have achieved our aim to implement high clinical standards and allow our findings to be compared with those published internationally [5,10-17]. Patient safety has improved, and not only by those treated but also by positive feedback from crews and hospital staff.

We are absolutely convinced that establishing a clinical governance system in parallel with the implementation of the new SOP was key in achieving our results. Our collected data suggests that it is possible to effectively change a flawed system that was in place for decades with a lot of commitment and implementing a new robust system that is based on a good template.

\section{Abbreviations}

BURP: Backward upward rightward pressure; BVM: Bag-valve-mask; ERC: European Resuscitation Council; GCS: Glasgow Coma Scale; HEMS: Helicopter Emergency Medical Service; LMA: Laryngeal Mask Airway; RSI: Rapid Sequence Intubation; SOP: Standard Operating Procedure; UK: United Kingdom.

\section{Competing interests}

The authors declare that they have no competing interests.

\section{Authors' contributions}

AS, PT and LH participated in designing the article, collection and analysis of data and organization of the process. AE and AP also provided feedback in all fields. All authors approved the final version of the manuscript.

\section{Authors' information}

Akos Soti: Emergency Physician, former Medical Director of Hungarian HEMS. Peter Temesvari: Emergency Physician, Medical Director of National Ambulance Service, Hungary.

Laszlo Hetzman: Orthopaedics and Trauma Surgeon, Medical Director of Hungarian HEMS.

Attila Eross: Anaesthetic Specialist Registrar, HEMS Physician.

Andras Petroczy: Consultant Anaesthetist, HEMS Physician.

\section{Acknowledgements}

The authors acknowledge the continuous support of Bela Burany, Tamas Berenyi, Judit Meray, the Working Group for Airway Management of the Association of Anaesthesiology and Intensive Care and the Hungarian Society of Emergency Medicine. They are grateful for the support of London's Air Ambulance, especially to Gareth Davies, David Lockey, Anne Weaver, Gareth Grier and Graham Chalk. Collaborators: Eva Bokor, Balazs Bondor, Laszlo Gorove, Zoltan Kurucz, Gary Spitzer. 
Received: 28 August 2014 Accepted: 16 December 2014

Published online: 09 January 2015

\section{References}

1. Hubble MW, Brown L, Wilfong DA, Hertelendy A, Benner RW, Richards ME. A meta-analysis of prehospital airway control techniques part I: orotracheal and nasotracheal intubation success rates. Prehosp Emerg Care. 2010;14(3):377-401.

2. Lossius HM, Roislien J, Lockey DJ. Patient safety in pre-hospital emergency tracheal intubation: a comprehensive meta-analysis of the intubation success rates of EMS providers. Crit Care. 2012, 16:R24.

3. Lockey D, Porter K. Prehospital anaesthesia in the UK: position statement. Emerg Med J. 2007;24(6):437-8.

4. London HEMS Standard Operating Procedure, Rapid Sequence Intubation. [http://www.ukhems.co.uk/ukhemssops.html]

5. Harris T, Lockey D. Success in physician prehospital rapid sequence intubation: what is the effect of base speciality and length of anaesthetic training? Emerg Med J. 2011;28(3):225-9.

6. UK HEMS Air Ambulance Working Group. Framework For a High Performing Air Ambulance (2008). [http://www.uk-hems.co.uk/governance.html]

7. Sellick BA. Cricoid pressure to prevent regurgitation of stomach contents during induction of anaesthesia. Lancet. 1961:404-6.

8. Bhatia N, Bhagat H, Sen I. Cricoid pressure: Where do we stand? J Anaesthesiol Clin Pharmacol. 2014;30(1):3-6.

9. Scally G, Donaldson LJ. Clinical governance and the drive for quality improvement in the new NHS in England. British Medical Journal. 1998; $317: 61-5$

10. Chesters A, Keefe N, Mauger J, Lockey D. Prehospital anaesthesia performed in a rural and suburban air ambulance service staffed by a physician and paramedic: a 16-month review of practice. Emerg Med J. 2014;31(1):65-8.

11. McQueen C, Crombie N, Hulme J, Cormack S, Hussain N, Ludwig F, Wheaton S. Prehospital anaesthesia performed by physician/critical care paramedic teams in a major trauma network in the UK: a 12 month review of practice. Emerg Med J. 2013 Oct 16. Epub 2013 Oct 16.

12. Von Vopelius-Feldt J, Benger JR. Prehospital anaesthesia by a physician and paramedic critical care team in Southwest England. Eur J Emerg Med. 2013;20(6):382-6.

13. Peters J, van Wageningen B, Hendriks I, Eijk R, Edwards M, Hoogerwerf N, Biert J. First-pass intubation success rate during rapid sequence induction of prehospital anaesthesia by physicians versus paramedics. Eur J Emerg Med. 2014 May 16. [Epub ahead of print].

14. Gunning M, O'Loughlin E, Fletcher M, Crilly J, Hooper M, Ellis DY. Emergency intubation: a prospective multicentre descriptive audit in an Australian helicopter emergency medical service. Emerg Med J. 2009;26(1):65-9.

15. Newton A, Ratchford A, Khan I. Incidence of adverse events during prehospital rapid sequence intubation: a review of one year on the London Helicopter Emergency Medical Service. J Trauma. 2008;64(2):487-92.

16. Helm M, Kremers G, Lampl L, Hossfeld B. Incidence of transient hypoxia during pre-hospital rapid sequence intubation by anaesthesiologists. Acta Anaesthesiol Scand. 2013;57(2):199-205.

17. Nakstad AR, Heimdal HJ, Strand T, Sandberg M. Incidence of desaturation during prehospital rapid sequence intubation in a physician-based helicopter emergency service. Am J Emerg Med. 2011;29(6):639-44.

\section{Submit your next manuscript to BioMed Central and take full advantage of:}

- Convenient online submission

- Thorough peer review

- No space constraints or color figure charges

- Immediate publication on acceptance

- Inclusion in PubMed, CAS, Scopus and Google Scholar

- Research which is freely available for redistribution 